\title{
JUSTIÇA AMBIENTAL E PLANEJAMENTO URBANO: CONSTRUINDO RESILIÊNCIA EM COMUNIDADES VULNERÁVEIS
}

\author{
Maria Cecília Trannin, Universidade do Estado do Rio de Janeiro - UERJ. \\ t.mariacecilia@gmail.com \\ Simara Ferreira Bruno, Universidade Estácio de Sá. \\ simaraferreirabruno@gmail.com
}

\section{RESUMO}

Considera-se como comunidades vulneráveis aquelas formadas pelos menos favorecidos, como os Povos Indígenas, os Afrodescendentes e os mais pobres. No contexto dos efeitos adversos causados pelas mudanças climáticas, essas comunidades geralmente são as primeiras e as que mais sofrem, pois possuem menor capacidade de adaptação. A expansão urbana sem planejamento adequado fez com que as cidades se tornassem cada vez mais descontínuas, contribuindo para o crescimento exponencial de áreas periféricas, colocando em evidência as diferenças entre as classes sociais e submetendo os menos favorecidos a uma carga maior de estressores tóxicos, discriminação, racismo e isolamento político. Nesse contexto, esse estudo traz como questão problema a seguinte pergunta: Como a justiça ambiental pode atuar por meio de um planejamento urbano participativo baseado na comunidade? O objetivo desse estudo foi compreender como formar resiliência nessas comunidades através do conceito de justiça ambiental. Esse artigo se desenvolveu por meio de uma pesquisa bibliográfica e concluiu que não há uma solução pronta que resolva as desigualdades urbanas que existem nas cidades, mas que a esperança se materializa através de um planejamento urbano participativo, baseado nos preceitos da justiça ambiental e do desenvolvimento sustentável. Para essa conquista, é preciso buscar um planejamento em equipe, capaz de unir moradores de comunidades vulneráveis aos governos locais, em parceria com a comunidade científica, criando bairros resilientes que não venham a sofrer gentrificação.

Palavras-Chave: Justiça Ambiental. Planejamento Urbano. Comunidades Vulneráveis. Resiliência.

Data de recebimento: $25 / 10 / 2020$

Data do aceite de publicação: 15/04/2021

Data da publicação: 30/04/2021 


\title{
JUSTIÇA AMBIENTAL E PLANEJAMENTO URBANO: CONSTRUINDO \\ RESILIÊNCIA EM COMUNIDADES VULNERÁVEIS
}

\section{ENVIRONMENTAL JUSTICE AND URBAN PLANNING: BUILDING RESILIENCE IN VULNERABLE COMMUNITIES}

\begin{abstract}
Vulnerable communities are those formed by the least favored, such as Indigenous Peoples, Afro-descendants and the poorest. In the context of the adverse effects caused by climate change, these communities are usually the first and the ones that suffer the most, as they have less capacity for adaptation. Urban sprawl without adequate planning has made cities increasingly discontinuous, contributing to the exponential growth of peripheral areas, highlighting the differences between social classes and subjecting the less fortunate to a greater burden of toxic stressors, discrimination, racism and political isolation. In this context, this study poses the following question as a problem: How can environmental justice work through participatory community-based urban planning? The purpose of this study was to understand how to form resilience in these communities through the concept of environmental justice. This article was developed through a bibliographical research and concluded that there is no ready solution that solves the urban inequalities that exist in the cities, but that the hope materializes through participatory urban planning, based on the precepts of environmental justice and development sustainable development. For this achievement, it is necessary to seek team planning, capable of uniting residents of vulnerable communities to local governments, in partnership with the scientific community, creating resilient neighborhoods that will not suffer from gentrification.
\end{abstract}

Keywords: Environmental Justice. Urban planning. Vulnerable Communities. Resilience.

\section{INTRODUÇÃO}

As consequências da mudança climática têm sido evidenciadas em todo o mundo, cada vez com ocorrências mais graves e, conforme afirmam os pesquisadores Shepard e Corbin-Mark (2009), são consideradas como o desafio social e político mais significativo do século XXI, o que se justifica pelo fato de que as emissões de $\mathrm{CO}_{2}$ promovidas pela atividade humana estão impactando (e continuarão a impactar) os sistemas naturais da Terra através do aquecimento global e aumento do nível do mar, afetando consideravelmente as gerações vindouras.

Ainda segundo Shepard e Corbin-Mark (2009), um agravante nesse cenário é que as comunidades vulneráveis, inclusive nas nações mais prósperas, são as primeiras e as mais atingidas pelos efeitos adversos do clima. Em geral, as áreas mais afetadas são comunidades de afrodescendentes, Povos Indígenas e comunidades de baixa renda, que são socioeconomicamente desfavorecidas, já sobrecarregadas desproporcionalmente pela qualidade ambiental deficiente, sendo menos capazes de se adaptar. Essas pessoas serão 


\section{JUSTIÇA AMBIENTAL E PLANEJAMENTO URBANO: CONSTRUINDO RESILIÊNCIA EM COMUNIDADES VULNERÁVEIS}

as primeiras a experimentar eventos extremos de calor, doenças respiratórias, doenças infecciosas transmitidas por vetores, insegurança alimentar e desastres naturais.

Trata-se de uma situação observada especialmente no mundo ocidental, onde se constata um componente de discriminação presente nessas comunidades vulneráveis, seja ele étnico, religioso, racial entre outros. Portanto, há o que se chama de Racismo Ambiental, que discrimina essas comunidades e precisa ser combatido. Por definição, é bem colocado por Selene Herculano (2008, p.16) que o Racismo Ambiental “[...] diz respeito às injustiças sociais e ambientais que recaem de forma desproporcional sobre etnias vulnerabilizadas".

Esse termo surgiu na década de 1980, nos Estados Unidos da América (EUA), após determinados eventos ocorridos em comunidades vulneráveis, como em 1982, na comunidade negra de Warren County na Carolina do Norte, quando seus moradores descobriram que um aterro para depósito de solo contaminado por PCB (bifenilos policlorados) seria instalado em sua comunidade. Surgiram protestos nacionais promovidos pelos afro-americanos contra o que, então, chamaram de Racismo Ambiental. Após esse marco, o movimento negro norte-americano conseguiu sensibilizar os congressistas, culminando na realização de uma pesquisa, feita pelo US General Accounting Office, que comprovou que a distribuição espacial de uma série de depósitos de resíduos químicos perigosos, bem como de indústrias muito poluentes, não era aleatória, estando sobrepostas à distribuição territorial das etnias pobres nos EUA (Herculano, 2008).

Essa discriminação acaba por acentuar o fato de que as classes sociais mais altas determinam que essa poluição ambiental seja "empurrada" para as periferias, fazendo com que os riscos ambientais sejam sofridos mais intensamente pelos mais pobres e pelas comunidades mais vulneráveis (Herculano, 2002).

Na realidade urbana brasileira, pode-se observar que, nas últimas décadas, as cidades têm passado por um enorme processo de crescimento populacional e territorial. Diante desse quadro de expansão urbana, essas cidades foram se tornando cada vez mais descontínuas, contribuindo para o crescimento exponencial de áreas periféricas, colocando em evidência as diferenças entre as classes sociais, além de transformar o espaço urbano em uma área cada vez mais fragmentada e segregada, onde nitidamente algumas áreas são ocupadas por classes de menor poder aquisitivo, por não terem condições financeiras de adquirir uma moradia mais próxima das áreas centrais da cidade. 


\section{JUSTIÇA AMBIENTAL E PLANEJAMENTO URBANO: CONSTRUINDO RESILIÊNCIA EM COMUNIDADES VULNERÁVEIS}

E nessas áreas marginalizadas observa-se a predominância de afrodescendentes, o que evidencia um racismo estrutural histórico, como é relatado por Silvio Almeida (2019), já que o racismo se articula com a segregação racial, ou seja, se observa uma divisão espacial de raças em localidades específicas, como bairros, guetos, periferias etc.

A questão do Racismo Estrutural é explicada por Almeida (2019, p.15), que afirma que "[...] o racismo é sempre estrutural, ou seja, de que ele é um elemento que integra a organização econômica e política da sociedade". Trata-se de uma manifestação "normal" de uma sociedade, que acaba por fornecer "[...] o sentido, a lógica e a tecnologia para a reprodução das formas de desigualdade e violência que moldam a vida social contemporânea". Portanto, o que ocorre é que as expressões/manifestações de racismo, sejam elas nas relações interpessoais ou na dinâmica das instituições, são manifestações de algo mais profundo, desenvolvido e nutrido "[...] nas entranhas políticas e econômicas da sociedade". Sendo assim, o racismo estrutural explica a existência do racismo ambiental.

Devido à essa constatação, foram realizados no Brasil o $1^{\circ}$ e $2^{\circ}$ Seminários Brasileiros contra o Racismo Ambiental, em 2005 e 2009, onde foram debatidos temas sobre as diferentes formas de violência sofridas pelas comunidades vulneráveis, em especial em relação aos aspectos relacionados com desenvolvimento e progresso, que deveriam ser baseados em projetos sustentáveis e sócio igualitários, mas o que se observa é que ocorrem de forma social e ambientalmente injustos.

Nesse cenário de marginalização das periferias, Jason Corburn (2017a) informa que pesquisadores e agências governamentais no mundo inteiro estão reconhecendo, cada vez mais, a necessidade de documentar exposições cumulativas, relacionadas à poluição, que os pobres urbanos e os afrodescendentes experimentam, além dos riscos ambientais relacionados com as mudanças climáticas. Esses "estressores tóxicos” podem exacerbar os impactos da exposição à poluição na saúde e incluem fatores sociais e econômicos, como discriminação, racismo, isolamento e exclusão política.

$\mathrm{O}$ mesmo autor explica que o combate a essas injustiças envolve estruturas e métodos de pesquisa que utilizem uma abordagem voltada para a justiça ambiental urbana, o que inclui a pesquisa participativa baseada na comunidade, a medição de estressores cumulativos e o mapeamento de ativos e riscos baseado na comunidade.

Enfatiza-se que o meio ambiente das sociedades humanas deve ser entendido como a interação entre ecológico (biológico), físico (natural e construído), social, 


\section{JUSTIÇA AMBIENTAL E PLANEJAMENTO URBANO: CONSTRUINDO RESILIÊNCIA EM COMUNIDADES VULNERÁVEIS}

político, estético e ambientes econômicos, sendo necessário um planejamento urbano que crie um ambiente saudável, visto o impacto que o ambiente construído causa na saúde pública. Ademais, têm sido vinculadas, explicitamente, questões de transporte e mal planejamento do uso da terra a resultados de saúde pública, como o aumento da obesidade, da asma e de efeitos negativos na saúde mental. Portanto, é preciso reconectar o planejamento urbano e a saúde pública (Corburn, 2004).

Diante disso, esse estudo traz como questão problema a seguinte pergunta: Como a justiça ambiental pode atuar por meio de um planejamento urbano participativo baseado na comunidade?

O principal objetivo desse estudo é de compreender como formar resiliência nessas comunidades vulneráveis através do conceito de justiça ambiental urbana. Como objetivos específicos, esse estudo procurou explicar o conceito de justiça ambiental; trazer informações pertinentes sobre o direito à moradia; informar o que são comunidades vulneráveis e os problemas que sofrem; Citar exemplos e parâmetros para o desenvolvimento de um planejamento urbano participativo com justiça ambiental.

Para a realização do trabalho foi escolhida a metodologia bibliográfica, com a busca de dados e informações em livros e artigos publicados sobre o tema. A pesquisa foi realizada nos meses de maio a julho de 2019, nos seguintes bancos de dados online: PubMed, Biblioteca Virtual em Saúde (BVS) e Google Acadêmico. Foram utilizados os descritores: justiça ambiental (environmental justice); planejamento urbano (urban planning); comunidades vulneráveis (vulnerable communities); resiliência (resilience). Os critérios de inclusão utilizados foram publicações que se encontrassem disponíveis na íntegra online, nos idiomas português e inglês, que pudessem colaborar com informações relevantes ao objetivo dessa pesquisa.

\section{JUSTIÇA AMBIENTAL, PLANEJAMENTO URBANO E A CONSTRUÇÃO DE RESILIÊNCIA}

\subsection{Justiça ambiental}

As discussões sobre justiça ambiental se iniciaram nos EUA, na década de 1960, tendo como objetivo primário garantir que afrodescendentes e grupos minoritários residentes nas periferias tivessem direito a respirar ar puro, estarem menos expostos a lixos tóxicos e garantissem acesso à saúde de qualidade (Alves \& Mariano, 2017). 


\title{
JUSTIÇA AMBIENTAL E PLANEJAMENTO URBANO: CONSTRUINDO RESILIÊNCIA EM COMUNIDADES VULNERÁVEIS
}

Na definição dada por Selene Herculano, tem-se que:

\begin{abstract}
Por 'Justiça Ambiental' entenda-se o conjunto de princípios que asseguram que nenhum grupo de pessoas, sejam grupos étnicos, raciais ou de classe, suporte uma parcela desproporcional das consequências ambientais negativas de operações econômicas, de políticas e programas federais, estaduais e locais, bem como resultantes da ausência ou omissão de tais políticas. Complementarmente, entende-se por 'Injustiça Ambiental' o mecanismo pelo qual sociedades desiguais destinam a maior carga dos danos ambientais do desenvolvimento a grupos sociais de trabalhadores, populações de baixa renda, grupos raciais discriminados, populações marginalizadas e mais vulneráveis (Herculano, 2008, p.3).
\end{abstract}

Por exemplo, concentrações de poluentes atmosféricos relacionados ao tráfego são frequentemente mais elevadas próximas a rodovias e estradas principais, e é comum que comunidades mais pobres e vulneráveis se desenvolvam próximas a essas vias. A mistura de gases e partículas nas emissões de gases de escape de veículos motorizados frescos é distinta de outros poluentes atmosféricos que se distribuem mais uniformemente em grandes áreas metropolitanas. Nesse caso, os principais poluentes incluem partículas ultrafinas (com < 0,1 mícron de diâmetro), carbono negro, PM10 (partículas com menos de 10 mícron de diâmetro), óxidos de nitrogênio, monóxido de carbono e compostos orgânicos voláteis. Assim, as pessoas que vivem ou passam tempo em locais adjacentes a estradas movimentadas estão mais expostas a esses poluentes. Estudos têm constatado, consistentemente, que morar mais perto de vias de tráfego pesado está associado à asma na infância e à função pulmonar reduzida, pior saúde cardiovascular, maior mortalidade e desenvolvimento do autismo (Brugge et al., 2015).

Essa questão de injustiça ambiental é particularmente aguda em áreas urbanas, onde os pobres e os afrodescendentes são frequentemente segregados em bairros onde uma série de insultos ambientais é agravada ainda mais devido a privação social e econômica, bem como pela privação política (Corburn, 2017a).

\subsection{A segregação, o direito à moradia e a dignidade}

A Constituição Federal Brasileira de 1988 define o direito à moradia como um dos direitos sociais fundamentais em seu artigo $6^{\circ}$, assim como prevê, em seu artigo $5^{\circ}$, que "todos são iguais perante a lei, sem distinção de qualquer natureza" (Brasil, 1988).

Cabe aqui uma breve análise sobre os direitos fundamentais, que são considerados como a expressão mais afeta à proteção constitucional dos direitos humanos dos cidadãos, estando ligados aos aspectos ou matizes constitucionais de proteção, no sentido de já se 


\title{
JUSTIÇA AMBIENTAL E PLANEJAMENTO URBANO: CONSTRUINDO RESILIÊNCIA EM COMUNIDADES VULNERÁVEIS
}

encontrarem positivados em uma Constituição Federal (Sarlet, 2012). É importante, também, lembrar que a base fundamental dos direitos humanos e dos direitos fundamentais é a dignidade da pessoa humana, que pode ser definida como uma qualidade inerente a todos os homens (Bernardo, 2014).

Dignidade da pessoa humana é definida por Ingo Wolfgang Sarlet (2009, p.37) da seguinte forma:

\begin{abstract}
A qualidade intrínseca e distintiva reconhecida em cada ser humano que o faz merecedor do mesmo respeito e consideração por parte do Estado e da comunidade, implicando, neste sentido, um complexo de direitos e deveres fundamentais que assegurem a pessoa tanto contra todo e qualquer ato degradante e desumano como venha lhe garantir as condições existenciais mínimas para uma vida saudável além de propiciar e promover sua participação ativa e corresponsável nos destinos da própria existência e da vida em comunhão com os demais seres humanos.
\end{abstract}

Mas, apesar de a base dos direitos fundamentais ser a dignidade da pessoa humana, de a moradia ser um direito fundamental e todos serem iguais perante a lei, o que se observa nas cidades é uma enorme segregação social e racial, onde os bairros mais bem localizados recebem melhor infraestrutura, são explorados pela especulação imobiliária e acabam sendo povoados por brancos de classe média a alta, restando aos pobres (onde se incluem boa parte dos afrodescendentes) as periferias, afastadas e que ficam esquecidas pelo governo, que ignora os direitos fundamentais dessa população, direitos esses que são previstos pela Constituição.

Nesse sentido, Ingo Wolfgang Sarlet (2003) comenta que os interesses do governo e os interesses privados dos agentes econômicos, muitas vezes desrespeitam e até mesmo aniquilam boa parte das conquistas sociais, colocando em risco a democracia e enfraquecendo o papel do Estado na sua condição de promover e assegurar os direitos fundamentais de boa parte de seus cidadãos. Nesse caso, a própria noção de cidadania, como o direito a ter direitos, fica sob grave ameaça, especialmente em vista do incremento dos índices de exclusão social, que em boa parte se deve aos efeitos negativos da globalização econômica, constituindo um fator de risco para a democracia.

$\mathrm{Na}$ interpretação de Madeiros, Grigio e Pessoa (2018), os problemas ambientais das cidades, e que levam a essa segregação social, são frutos dos processos de urbanização rápida e intensa, muitas vezes, desordenada, que constituíram (e ainda constituem) a formação das cidades brasileiras. Esse modelo de urbanização é característico das sociedades contemporâneas na maioria dos países em desenvolvimento, o que pode trazer uma série de consequências negativas. Por exemplo, os mesmos autores dizem que grande 


\section{JUSTIÇA AMBIENTAL E PLANEJAMENTO URBANO: CONSTRUINDO RESILIÊNCIA EM COMUNIDADES VULNERÁVEIS}

parte das cidades existentes apresenta sérios problemas de infraestrutura urbana, o que torna seus espaços diferenciados, segmentados e vulneráveis. Entre as infraestruturas urbanas, pode-se citar a ausência de saneamento básico, descarte inadequado de resíduos sólidos e domicílios situados em lugares impróprios. Esses são alguns exemplos, dentre tantos outros, dos problemas que a falta de planejamento urbano causa para certos grupos populacionais, principalmente os de menor renda.

Para compreender como se deu a ocupação e construção do espaço urbano brasileiro, é preciso retroceder um pouco no tempo e entender a história de ocupação do Brasil, onde se verifica que o espaço urbano foi sendo criado de forma desigual. Pode-se dizer que o processo de urbanização no país começou a se desenvolver, de fato, a partir do século XVIII, e que devido as mudanças decorrentes no processo estrutural só veio atingir a forma de urbanização atual a partir do século XX. Durante o período colonial, o processo de urbanização pouco se desenvolveu, tendo um crescimento de $3 \%$ entre os anos de 1890 e 1920. Somente nos anos de 1920 até 1940 é que o Brasil viu as suas taxas de urbanização triplicarem, chegando a 31,24\% (Santos, 1993).

Conforme explica Milton Santos (1993), a urbanização brasileira se iniciou de forma litorânea, até tornar-se praticamente generalizada a partir do final do século XX. Com a urbanização que se avolumou no país, a residência dos trabalhadores agrícolas foi se tornando cada vez mais urbana, não havendo mais a antiga separação tradicional entre um Brasil urbano e um rural. Com isso, surgiram as cidades milionárias, as cidades intermediárias ao lado destas, e as cidades locais, todas adotando um modelo geográfico de crescimento espraiado, com tamanho desmesurado, que é causa e efeito da especulação imobiliária.

Em outra publicação, Milton Santos (2004) diz ser importante reconhecer que o espaço urbano evolui através do movimento da sociedade, através de suas características e por seu funcionamento, pelo que o espaço oferece a alguns e recusa a outros, pela seleção de localização feita entre as atividades e entre os homens. É, portanto, o resultado de uma ação coletiva que reproduz as relações sociais.

Nesse sentido, ao avaliar a questão da justiça ambiental urbana, Jason Corburn (2017a) afirma que os bairros urbanos tendem a se concentrar e colocar pessoas vulneráveis em ambientes tóxicos, reservando lugares nas cidades onde os pobres e os afrodescendentes tendem a estar desproporcionalmente expostos a maiores riscos 


\section{JUSTIÇA AMBIENTAL E PLANEJAMENTO URBANO: CONSTRUINDO RESILIÊNCIA EM COMUNIDADES VULNERÁVEIS}

ambientais, como poluição do ar, chumbo na pintura e na água, indústrias poluidoras, falta de saneamento básico entre outros riscos.

Assim surgiram as periferias, locais marginalizados, onde há pouco ou nenhum interesse da especulação imobiliária ou do Estado, que acabam por virarem "polos da pobreza", atraindo as camadas menos favorecidas da população, muitas vezes para viverem em condições sub-humanas. Essa população, muitas vezes sem acesso a empregos, a bens e serviços essenciais na periferia, tem que se deslocar cotidianamente para as áreas centrais das cidades para obtê-los, o que fomenta a crise urbana, fazendo com que essa população só empobreça e sofra a degradação de suas condições de existência. Com isso, a cidade em si torna-se cocriadora de pobreza, pelo abandono do Estado, dos agentes imobiliários e da sociedade em geral a estas localidades (Santos, 1993).

Segundo Roberto Lobato Corrêa (1989), o espaço urbano é o conjunto de diferentes usos da terra, podendo ser definido como espaço das cidades, onde ocorre um conjunto de atividades, justaposto de casas e edifícios, desenvolvendo práticas econômicas, sociais e culturais. Estes usos definem áreas como o centro da cidade (onde há a concentração de atividades comerciais, de serviços, de gestão) das áreas industriais e residenciais, de lazer, entre outras. Todas estas partes mantêm relações espaciais entre si, porém com variações em suas intensidades. Dessa forma o espaço se torna um reflexo da sociedade, onde se tem as práticas políticas e diversidades culturais, sendo economicamente produzido, transformado e apropriado com base nas ações racionais e afetivas. Este complexo conjunto de usos da terra é a organização espacial da cidade, ou o espaço urbano, que se mostra como um espaço fragmentado, articulado, condicionante das ações sociais e o reflexo das mesmas, sendo compreendido como um conjunto de símbolos e como um campo de lutas, envolvendo principalmente as classes sociais.

Esse modelo de construção das cidades em pouco tempo tornou-se insustentável, pois a falta de planejamento criou, além da segregação de parte da população, uma série de problemas como poluição, precarização da mobilidade urbana, violência, esgotamento dos recursos naturais, deficiência energética e ausência de locais adequados para destinação do lixo. Com isso veio a necessidade premente de mudanças, levando ao desenvolvimento de projetos voltados para a construção de cidades inteligentes. E, na visão contemporânea, estas também precisam ser sustentáveis e humanas, conforme colocam Albino, Berardi e Dangelico (2015), segundo a qual as cidades também devem 


\section{JUSTIÇA AMBIENTAL E PLANEJAMENTO URBANO: CONSTRUINDO RESILIÊNCIA EM COMUNIDADES VULNERÁVEIS}

responder às necessidades das pessoas por meio de soluções sustentáveis para seus aspectos sociais e econômicos.

Assim, como forma de solucionar essa desigualdade vem se investindo no conceito de cidades inteligentes, humanas e sustentáveis, onde se busca o uso da tecnologia para criar o espaço urbano do futuro, seguro, ambientalmente sustentável e eficiente (Pires, 2020). Nesse cenário, são discutidos aspectos emergentes sobre o planeamento urbano, com foco na era digital, onde a distribuição do espaço urbano com vistas na expansão capitalista ganha um novo formato.

Em uma cidade inteligente, humana e sustentável, todas as suas estruturas (como os setores de energia, água, transportes, saneamento básico etc.) são projetadas, construídas e mantidas com a utilização de recursos e materiais avançados, utilizando sensores, dispositivos eletrônicos e redes integrados e que fazem interface com sistemas computadorizados compostos por bancos de dados, facilidades de rastreamento e algoritmos de tomada de decisão. Diante disso, a visão das cidades do futuro se apresenta com base na integração da ciência e da tecnologia através de sistemas de informação. Esse futuro exige repensar as relações entre governo, gestores municipais, empresas, universidades e comunidade científica (Pires, 2020).

\subsection{Comunidades e vulnerabilidades}

Segundo Madeiros, Grigio e Pessoa (2018), o crescimento das populações, a urbanização acelerada, o enfraquecimento dos governos, a instalação de domicílios em locais impróprios, a concentração de renda na mão de poucos e os impactos humanos causados ao meio ambiente estão entre os fatores que promovem a desigualdade ambiental e geram situações de vulnerabilidade das cidades, principalmente das periferias e de boa parte dos seus habitantes.

Segundo Cole et al. (2017), estudos de justiça ambiental demonstram que a maior carga de efeitos negativos do meio ambiente está concentrada entre as rendas mais baixas e as minorias raciais ou étnicas. Associado a isso, muitas pesquisas epidemiológicas documentam a importância da segregação espacial socioeconômica e racial no estudo das iniquidades e geografias da saúde, pois essa segregação cria uma exposição extremamente desigual a piores ambientes sociais e físicos de vizinhança, pobreza concentrada e menos oportunidades econômicas e educacionais. Além disso, os aspectos físicos dos bairros, como a presença ou ausência de parques, infraestrutura adequada para pedestres, e pontos 


\section{JUSTIÇA AMBIENTAL E PLANEJAMENTO URBANO: CONSTRUINDO RESILIÊNCIA EM COMUNIDADES VULNERÁVEIS}

de venda de varejo que forneçam alimentos saudáveis, também podem afetar a saúde dos residentes.

Bairros que possuem alta proporção de populações socialmente vulneráveis também são os que experimentam uma deterioração crescente do ambiente construído que protege a saúde e a propriedade. Por exemplo, esses bairros têm menos acesso a empregos, trânsito e serviços de saúde de qualidade e outros serviços públicos, além de apresentarem maior probabilidade de estar localizados próximos a instalações indesejáveis, como incineradores de resíduos, aterros sanitários ou refinarias que contribuem para problemas de saúde pública (Meyer et al., 2018).

A ausência de planejamento urbano, segundo Madeiros, Grigio e Pessoa (2018), acaba por se constituir em um dos fatores que deixam as cidades e seus moradores mais vulneráveis, ficando expostos aos vários riscos decorrentes de processos desordenados de ocupação territorial. Além disso, há os fatores naturais, que com as mudanças climáticas perderam o caráter de fenômenos raros e se tornaram mais frequentes, entre eles as chuvas torrenciais, terremotos, períodos de estiagens prolongadas, entre outros. Os autores alegam que essas ocorrências, que agora estão mais frequentes em vários lugares do mundo, estão impondo uma maior capacidade de resposta da gestão das cidades, em especial das comunidades mais vulneráveis, que sofrem muito mais com essas condições climáticas adversas. Assim, seus moradores estão mais sujeitos a sofrerem as consequências de fenômenos adversos das mudanças climáticas, bem como aqueles de natureza ambiental produzidos pelos próprios seres humanos, entre eles os associados a descarte de lixo, de efluentes e a falta de saneamento básico. Os autores também destacam que, na realidade brasileira, mesmo havendo políticas públicas e privadas direcionadas para o planejamento e ordenamento das cidades, os gestores continuam agindo de forma paliativa quando precisam enfrentar casos de calamidade pública, o que demonstra falta de organização com os gastos públicos, visto que se investe mais em medidas de contenção ou mitigação do que em medidas preventivas. Ademais, favelas continuam a serem erguidas e espaços públicos são ocupados sem nenhum tipo de planejamento urbano.

Segundo Guedes et al. (2020), ao reunirem conceitos de vários autores, o planejamento urbano é a ciência de promover a combinação de muitas variáveis naturais, sociais e de engenharia para guiar o crescimento da cidade e resolver seus problemas, além de fornecer as necessidades para uma vida urbana balanceada, prevendo o número 


\section{JUSTIÇA AMBIENTAL E PLANEJAMENTO URBANO: CONSTRUINDO RESILIÊNCIA EM COMUNIDADES VULNERÁVEIS}

possível de pessoas no espaço e satisfazer suas necessidades de vida, trabalho e outras atividades, com necessidades de infraestrutura (água, energia, trânsito etc.). Ademais, o planejamento urbano precisa ser equilibrado e atender às necessidades da geração atual de recursos e energias, sem consumir a parcela das gerações futuras, ou seja, o planejamento urbano deve ser sustentável.

Corburn (2017b) afirma que, se a comunidade global for séria sobre os objetivos de desenvolvimento sustentável e justiça ambiental, uma maior atenção deve ser dada à compreensão e atuação para melhorar os planejamentos urbanos, em especial com atenção aos bairros periféricos, as condições de vida e as condições sociais e econômicas que podem promover a equidade em saúde e bem-estar.

\subsection{Resiliência}

Pode-se definir resiliência como a capacidade das comunidades de reduzir ou ajustar-se a vulnerabilidades de risco, incluindo a implementação de estratégias para reduzir o risco ambiental, aumentando a prontidão a desastres e perigos e permitindo a ação coletiva. Em geral, as atividades de resiliência mais comuns, que envolvem o ambiente construído, como planos de mitigação de riscos, regulamentações, investimentos em infraestrutura e programas de aquisição de terras, são lideradas pelo governo, e a participação pública nesses processos pode ficar limitada ou ser dominada por grupos de interesse ou residentes de elite que tenham tempo e recursos para participar. Nesse caso, minorias raciais, marginalizadas e de baixa renda acabam por terem menos voz para influenciar esses tipos de ações, apesar de enfrentarem maior risco de mudanças ambientais e desastres (Meyer et al., 2018).

Na concepção de Madeiros, Grigio e Pessoa (2018, p.248) “um futuro de maior capacidade de resiliência e adaptação a cenários marcados por incertezas e riscos seria a direção para a qual as cidades deveriam seguir". Os autores dizem que deve-se buscar por uma sociedade menos desigual, tanto socialmente como ambientalmente, com a finalidade de se tornar resiliente frente às intempéries que são impostas tanto pela ação da natureza, como pela ação antrópica. Ainda para os autores, para se conquistar a meta de construir uma cidade resiliente é preciso perpassar por todas as instâncias envolvidas, desde os gestores até a população, em especial estes últimos, pois são os que residem no local e possuem consciência de suas necessidades. Nesse caso, é preciso conscientizar a população dos riscos aos quais se encontram suscetíveis e integrá-la aos processos de 


\section{JUSTIÇA AMBIENTAL E PLANEJAMENTO URBANO: CONSTRUINDO RESILIÊNCIA EM COMUNIDADES VULNERÁVEIS}

tomada de decisão. A partir do instante em que uma comunidade se torna agente de sua mudança, participando do processo de tomada de decisão, é que se consegue alcançar uma maior justiça ambiental e solidariedade na gestão pública. Portanto, é apenas com o apoio da população que as cidades poderão vir a se tornar mais resilientes, e é através de uma gestão participativa que se tornará o governo mais transparente.

\subsection{Planejamento urbano participativo}

A justiça ambiental e a sustentabilidade são lentes compatíveis, mas a ação para a equidade muitas vezes está em falta nas iniciativas de sustentabilidade urbana (Hornik, Cutts \& Greenlee, 2016). De fato, os processos de planejamento urbano são influenciados por uma hierarquia de interesses organizados que controlam as decisões de uso da terra, ou seja, onde parques ou espaços abertos devem ser construídos, onde empreendimentos comerciais ou residenciais devem ser autorizados e até onde as indústrias devem permanecer. Esta hierarquia tradicionalmente coloca os interesses orientados para o crescimento econômico no topo, deixando outros interesses como equidade social, sustentabilidade ambiental e promoção da saúde em segundo plano. Além disso, a falta de comunicação das partes interessadas e uma tendência para o planejamento do uso da terra que não considere o desenvolvimento abrangente de um bairro ou distrito, assim como as diferentes necessidades de seus residentes, também contribuem para decisões de planejamento urbano que não abordem o bem-estar e a saúde de maneira abrangente (Cole et al., 2017).

Espaços urbanos e equidade em saúde são dois dos conceitos mais desafiadores para a saúde ambiental do século XXI. Atualmente existem mais pessoas vivendo nas cidades do que em qualquer outro momento da história, e as desigualdades na saúde estão aumentando. As iniquidades em saúde são diferenças evitáveis nas condições sociais, ambientais e políticas que moldam a morbidade e a mortalidade, e sobrecarregam desproporcionalmente as minorias menos favorecidas. Ao interligar o lugar urbano e as iniquidades em saúde, a pesquisa e a ação trazem à tona os desafios de alcançar a justiça ambiental urbana (Corburn, 2017b).

Embora a saúde pública e o planejamento urbano tenham surgido com o objetivo comum de prevenir surtos urbanos de doenças infecciosas, há pouca sobreposição entre os dois campos hoje em dia, e essa separação dos campos acabou por contribuir para a existência de esforços descoordenados que abordem a saúde das populações urbanas e 


\section{JUSTIÇA AMBIENTAL E PLANEJAMENTO URBANO: CONSTRUINDO RESILIÊNCIA EM COMUNIDADES VULNERÁVEIS}

um fracasso geral em reconhecer as ligações entre, por exemplo, o ambiente construído e as disparidades de saúde enfrentadas por populações de baixa renda e afrodescendentes (Corburn, 2004).

O resultado da desconexão do trabalho nos dois campos é que ambas as áreas estão deixando de considerar, de forma significativa, os fatores econômicos, sociais e políticos que contribuem para as disparidades de saúde pública. Assim, enquanto a saúde pública está cada vez mais concentrada em fatores biomédicos que podem contribuir para diferentes taxas de morbidade e mortalidade entre os menos favorecidos, e está apenas começando a investigar seriamente o papel das decisões de uso da terra e como o ambiente construído influencia a saúde da população, a prática de planejamento urbano mostra poucos sinais de retorno a uma de suas missões originais que é a de tratar da saúde dos moradores de comunidades carentes (Corburn, 2004).

A urbanização e a criação do ambiente construído são as principais forças motrizes das mudanças ambientais e climáticas, e estão intimamente ligadas a questões de saúde pública. Por isso, torna-se estratégico discutir o papel do planejamento ambiental urbano em associação com o desenvolvimento sustentável e a justiça ambiental, que devem fornecer a base normativa para pesquisas interdisciplinares que considerem o papel do ambiente construído na criação de passivos ambientais e iniquidades em saúde, e que enfoquem sobre as disparidades nos resultados climáticos e de saúde (Rosenthal \& Brandt-Rauf, 2006).

Um dos primeiros princípios da justiça ambiental é que as comunidades devem "falar por si" na caracterização dos perigos e riscos que enfrentam, bem como sobre as oportunidades que se apresentam e o que deve ser feito para melhorar o bem-estar da comunidade. A pesquisa participativa baseada na comunidade (PPBC) é uma abordagem à pesquisa e ao conjunto de métodos que procura transformar o empreendimento científico envolvendo as comunidades no processo de pesquisa. A PPBC deve, tipicamente, envolver colaborações acadêmico-comunitárias nas quais o conhecimento e o poder são compartilhados entre os parceiros em todos os aspectos do processo de pesquisa, que são: fazer, interpretar e agir sobre a ciência. Assim, o processo visa elevar o conhecimento da comunidade, incluindo a história dos lugares e as biografias dos moradores, ao mesmo tempo em que também desafia a dinâmica tradicional de poder no processo de pesquisa (Corburn, 2017a). 


\section{JUSTIÇA AMBIENTAL E PLANEJAMENTO URBANO: CONSTRUINDO RESILIÊNCIA EM COMUNIDADES VULNERÁVEIS}

As colaborações para a justiça ambiental entre a comunidade e a universidade devem cultivar parcerias recíprocas de longo prazo, baseadas na comunidade, onde a universidade e os moradores coproduzem o conhecimento e a ação em direção a uma sociedade mais justa, sustentável e democrática (Loh, 2016).

Nesse caso, um direcionamento para uma pesquisa-ação participativa pode melhorar o conhecimento científico e a capacidade da comunidade de abordar a resiliência a desastres naturais e a justiça ambiental. Evidências de pesquisas mais recentes sugerem que a participação dos residentes aumenta a avaliação dos riscos ambientais, aumenta a conscientização e capacita os moradores a lutar pela distribuição equitativa de adaptações de risco ambiental e climático. No entanto, a avaliação de riscos e os processos de planejamento urbano ainda operam com frequência dentro de grupos especializados, sem envolvimento significativo da comunidade. Essa fragmentação resulta, em parte, da falta de reconhecimento pela experiência da comunidade em adaptações do ambiente construído e, também, de ferramentas educacionais para apoiar o envolvimento dos residentes nos processos de planejamento do ambiente construído (Meyer et al., 2018).

Em seu estudo, Jason Corburn (2017b) sugere que uma abordagem mais relacional ou integrada com a comunidade deve ser realizada para promover justiça ambiental e melhorar a capacidade da saúde pública de enfrentar os desafios do século XXI. É preciso que planejamentos urbanos futuros enfoquem a saúde pública ambiental na formação de um local urbano saudável e, para tanto, a práticas devem incluir a elaboração de mapas orientada pela comunidade em questão, a saúde em todas as políticas, promoção de serviços ecossistêmicos urbanos para a saúde e abordagens participativas e integradas para a urbanização de favelas urbanas.

Assim, a primeira tarefa dos responsáveis pelo planejamento urbano deve ser mapear as desigualdades ambientais relevantes, em especial para a saúde, a fim de identificar as necessidades de planejamento de intervenções. Para isso, devem ser desenvolvidos indicadores adequados para mapear essas desigualdades ambientais e de nível socioeconômico, com base em evidências científicas publicadas associadas às contribuições dos interessados locais. Intervenções de planejamento adequadas compreendem, principalmente, o planejamento de transporte e gerenciamento de espaços verdes, o que envolve promover ações que gerem ar limpo e redução de ruído (Flacke et al., 2016). 


\section{JUSTIÇA AMBIENTAL E PLANEJAMENTO URBANO: CONSTRUINDO RESILIÊNCIA EM COMUNIDADES VULNERÁVEIS}

Portanto, um exemplo é o planejamento do transporte urbano. Nesse sentido, Epting (2015a) ressalta que os municípios devem dedicar recursos para implementar um sistema de transporte público que, além de eficaz, os usuários considerem esteticamente agradável, visto que terão que utilizá-lo diariamente, considerando que a mobilidade limitada de transporte é uma das questões que mais afeta os moradores pobres de periferias. $O$ transporte inadequado afeta muitas pessoas, sendo primordial que os planejadores e engenheiros abordem o problema e busquem produzir melhores resultados para os moradores e para o meio ambiente.

Outra questão fundamental é o ambiente urbano em si onde vivem essas comunidades carentes. É fato, e está bem documentado, que os ambientes da vizinhança, tanto sociais quanto físicos, afetam a saúde e o bem-estar dos moradores. Também é comprovado que a exposição ao espaço verde está associada a melhores resultados de saúde física e mental. Assim, em relação ao planejamento urbano nesse sentido, é necessário concentrar mais esforços no intuito de melhorar os ambientes físicos e naturais nas cidades, em especial nas periferias, através da criação de parques e jardins, pois eles têm a hipótese de melhorar a saúde através da promoção da atividade física, promovendo apoio social, reduzindo o estresse e a exposição à poluição do ar e a toxinas ambientais. Essas intervenções verdes são frequentemente descritas como medidas de sustentabilidade ou resiliência, e se tornam centrais para a abordagem de uma "cidade saudável". Para isso, é preciso planejamento urbano e construção de infraestrutura municipal em torno de ambientes urbanos saudáveis e melhores resultados de saúde e justiça ambiental para os residentes carentes (Cole et al., 2017).

Porém, é importante colocar aqui uma questão, pois um problema comum que pode ocorrer é que ao levar melhorias para bairros de periferia, como a criação de áreas verdes e de lazer, melhor iluminação, segurança, saneamento e infraestrutura, acaba surgindo o processo de gentrificação, que se traduz em valorização imobiliária do bairro em questão, levando a especulação imobiliária a agir, aumentando o valor dos imóveis e aluguéis. Com isso, pessoas de melhor renda começam a se mudar para esses bairros e os antigos moradores já não conseguem mais pagar o exigido pela especulação imobiliária para continuar morando nesses locais, e são obrigados a se mudar. Assim, é fundamental diferenciar um processo de revitalização de um bairro de um processo de gentrificação, que sempre se dá em parceria com a especulação imobiliária. 


\section{JUSTIÇA AMBIENTAL E PLANEJAMENTO URBANO: CONSTRUINDO RESILIÊNCIA EM COMUNIDADES VULNERÁVEIS}

Ou seja, a revitalização de um local deve ter o intuito de beneficiar os moradores, e o dinheiro público dos impostos é gasto para promover as melhorias necessárias. Mas, quando essa "revitalização" se associa a especulação imobiliária, interesses que não são os dos moradores são priorizados, no intuito de valorizar os imóveis locais e lucrar com isso, muito as custas de dinheiro público, visto que as melhorias realizadas geralmente são custeadas pelo Estado. Dessa forma, as decisões sobre melhorias no bairro não devem ser tomadas "de cima para baixo". Devem envolver os moradores. Conforme defende Epting (2015b), trazer os residentes para as conversas sobre as decisões que terão consequências diretas para eles é fundamental, pois dá aos moradores um papel na definição da identidade de sua comunidade. Essa atitude de união indica um passo importante em direção ao planejamento urbano participativo, o que alivia parte do dano que pode vir a ser causado por uma futura gentrificação.

Os pesquisadores Meyer et al. (2018) sugerem que um projeto de planejamento urbano participativo, que desenvolva resiliência, deve ser feito com base em um ciclo de retroalimentação de transferência de conhecimento entre pesquisadores e parceiros engajados, em uma comunidade socialmente vulnerável, em busca de justiça ambiental, e deve ter os seguintes objetivos: 1) compreender totalmente a extensão do risco que a comunidade enfrenta; 2) alinhar metas de pesquisa com a visão de justiça ambiental da comunidade; 3) disseminar novos conhecimentos em quadros culturalmente apropriados; e 4) posicionar os parceiros da comunidade para atuar em um conjunto de estratégias fundamentadas na realidade empírica. Este método pede que especialistas e pesquisadores trabalhem lado a lado com parceiros e residentes da comunidade, para melhorar sua resiliência. Através do estabelecimento de parcerias e do desenvolvimento de uma agenda unificada que estimule a confiança, o coaprendizado e o envolvimento total é imperativo. Criar e facilitar um "ecossistema de aprendizado" resulta em uma maior compreensão de questões complexas por todos os participantes do projeto, e usa abordagens e processos que apoiam o empoderamento da comunidade.

Entre os projetos já existentes ao redor do planeta, as soluções baseadas na natureza (NBS) estão cada vez mais sendo aplicadas em planejamentos urbanos para orientar o projeto de paisagens e criar cidades resilientes, para que possam atingir metas de desenvolvimento econômico com resultados benéficos para o meio ambiente e para a sociedade. O conceito de NBS está intimamente relacionado a outros conceitos, como os de sustentabilidade, resiliência, serviços ecossistêmicos, recursos humanos e ambientais 


\section{JUSTIÇA AMBIENTAL E PLANEJAMENTO URBANO: CONSTRUINDO RESILIÊNCIA EM COMUNIDADES VULNERÁVEIS}

acoplados e infraestrutura verde. Ademais, as NBS representam uma abordagem de desenvolvimento mais eficiente e econômica do que as abordagens tradicionais (Lafortezza et al., 2018).

Esse pensamento se baseia nas descobertas sustentadas pela comunidade científica, que entende a necessidade de transmutar da construção "cinza" para a construção de infraestrutura "verde", para restaurar o equilíbrio ecológico dentro da paisagem urbana com o duplo propósito de desenvolver ecossistemas resilientes e sociedades mais saudáveis. Essa premissa se fundamenta no papel primordial que a natureza desempenha através da prestação de serviços ecossistêmicos no apoio à economia, bem como a subsistência dos cidadãos. Os benefícios de investir na restauração da infraestrutura verde em áreas urbanas não é apenas ecológica e socialmente desejável, mas também economicamente vantajoso (Lafortezza et al., 2018).

Por fim, para promover a justiça ambiental há a necessidade maior de examinar como os diversos grupos de partes interessadas constroem teorias de mudança dentro de suas realidades. Mas essas teorias devem corresponder às expectativas de mudança em direção à justiça e à sustentabilidade. Para operacionalizar essas teorias, as partes interessadas devem definir a preocupação com as injustiças ambientais que sofrem, os processos que elas veem como contribuintes para a injustiça e os recursos que podem ser utilizados para alcançar as mudanças que elas articulam. Assim, o objetivo é o de extrair elementos relevantes de diferentes teorias e destacar semelhanças e diferenças entre eles, direcionando maneiras para a promoção de um planejamento urbano participativo que traga as melhorias necessárias para as comunidades em questão (Hornik, Cutts \& Greenlee, 2016).

\section{CONSIDERAÇÕES GERAIS}

Diante do cenário aqui exposto, observa-se que ainda não há uma solução pronta que possa resolver as desigualdades urbanas que existem hoje nas cidades. Não existe uma política pública que combata os complexos processos sociais que criam essas desigualdades urbanas em diferentes contextos.

Respondendo à questão problema dessa pesquisa e ao objetivo principal, concluiuse que a solução para o problema das cidades mal planejadas é o desenvolvimento de um planejamento urbano participativo que tenha como premissa a justiça ambiental e o 


\section{JUSTIÇA AMBIENTAL E PLANEJAMENTO URBANO: CONSTRUINDO RESILIÊNCIA EM COMUNIDADES VULNERÁVEIS}

desenvolvimento sustentável. Para que isso possa ocorrer de forma efetiva é preciso formar resiliência nessas comunidades vulneráveis por meio da capacitação de seus moradores, através do conceito de justiça ambiental urbana.

Através da parceria entre moradores, governo e comunidade científica, é possível identificar os principais problemas que afetam essas comunidades e direcionar os recursos necessários para solucioná-los, resolvendo questões como falta de saneamento básico, ausência de coleta de lixo, pavimentação e iluminação de ruas, manutenção de terrenos baldios, avaliação de risco de construções em encostas ou beira de rios, entre outras. Assim, evita-se a proliferação de vetores de doenças, reduz-se o risco de enchentes, de deslizamentos, melhora-se a segurança, entre outros benefícios.

Também se detecta ausências de áreas de lazer, de escolas, creches, parques, má infraestrutura de transporte, exposição à agentes poluidores, ruídos entre uma série de outros problemas que podem estar afetando essas comunidades. Ao combater esses problemas, melhora-se a segurança, e qualidade de vida e da saúde dessa população, o que se traduz em economia para os cofres públicos no gasto com saúde pública.

Porém, há o grande problema de especulação imobiliária, que procura direcionar as ações e investimentos Estatais em prol de seus interesses financeiros, incentivando melhorias infraestruturais nos bairros que possam vir a ser explorados futuramente com a venda de imóveis de valor mais elevado, levando à gentrificação dos mesmos, o que acaba por expulsar os antigos moradores do local, que mais uma vez perdem o direito a uma moradia em local digno.

Todavia, a esperança de um planejamento urbano eficaz precisa ser fomentada, e a busca por um trabalho em equipe, capaz de unir os moradores de comunidades carentes e vulneráveis e dos governos locais, em parceria com a comunidade científica, deve ser alcançada, criando bairros e cidades resilientes onde essa população possa continuar morando.

Afinal, é preciso reorientar o debate em torno da justiça ambiental para afastar a segmentação social. É preciso repensar a forma como as cidades estão sendo construídas e expandidas, pois a forma que vem sendo feita apenas reproduz e potencializa a pobreza, as desigualdades e o racismo, além de sobrecarregar as comunidades e populações mais vulneráveis com maior carga de poluição e efeitos adversos. É preciso investir em um planejamento urbano em parceria com essas comunidades, tendo como objetivo melhorar a qualidade de vida de seus moradores, com justiça ambiental. 


\section{JUSTIÇA AMBIENTAL E PLANEJAMENTO URBANO: CONSTRUINDO \\ RESILIÊNCIA EM COMUNIDADES VULNERÁVEIS}

\section{REFERÊNCIAS}

Albino, V., Berardi, U., \& Dangelico, R. M. (2015). Smart cities: definitions, dimensions, performance, and initiatives. Journal of Urban Technology, 22(1), 3-21.

Almeida, S. L. (2019). Racismo estrutural. São Paulo: Pólen.

Alves, M. W. F. M., \& Mariano, E. B. (2017). Liberdade como garantia de justiça climática: o papel do indivíduo em economia de baixo carbono. Anais do XXIV Simpósio de Engenharia de Produção, Bauru (SP), 1-11.

Bernardo, A. A. (2014). Direito humanos: a "retórica" do universalismo em uma sociedade global multicultural. Espaço Jurídico, 15(1), 19-132.

Brasil. Presidência da República. Casa Civil. Subchefia para Assuntos Jurídicos. (1988). Constituição da República Federativa do Brasil de 1988. Brasília-DF.

Brugge, D., Patton, A. P., Bob, A., Reisner, E., Lowe, L., Bright, O. M., Durant, J. 1., Newman, 1., \& Zamore, W. (2015). Developing community-level policy and practice to reduce traffic-related air pollution exposure. Environmental Justice, 8(3), 95-104.

Cole, H. V. S., Lamarca, M. G., Connolly, J. J. T., \& Anguelovski, I. (2017). Are green cities healthy and equitable? Unpacking the relationship between health, green space and gentrification. Journal of Epidemiology and Community Health, 209201.

Corburn, J. (2004). Confronting the challenges in reconnecting urban planning and public health. American Journal of Public Health, 94(4), 541-546.

Corburn, J. (2017a). Concepts for studying urban environmental justice. Current Environmental Health Reports, 4(1), 61-67.

Corburn, J. (2017b). Urban place and health equity: critical issues and practices. International Journal of Environmental Research and Public Health, 14(2).

Corrêa, R. L. (1989). Espaço urbano. São Paulo: Ática. 


\section{JUSTIÇA AMBIENTAL E PLANEJAMENTO URBANO: CONSTRUINDO RESILIÊNCIA EM COMUNIDADES VULNERÁVEIS}

Epting, S. (2015a). A different trolley problem: the limits of environmental justice and the promise of complex moral assessments for transportation infrastructure. Science and Engineering Ethics, 22(6), 1781-1795.

Epting, S. (2015b). An applied mereology of the city: unifying science and philosophy for urban planning. Science and Engineering Ethics, 22(5), 1361-1374.

Flacke, J., Schüle, S. A., Köckler, H., \& Bolte, G. (2016). Mapping environmental inequalities relevant for health for informing urban planning interventions - a case study in the city of Dortmund, Germany. International Journal of Environmental Research and Public Health, 13(7), 711-729.

Guedes, A. L. A., Soares, C. A. P., Chinelli, C. K., Lima, E. G., Gomes, J. A. P., \& Gandelman, L. O planejamento urbano rumo à cidade inteligente. In: A. L. A. Guedes, C. A. P. Soares, \& M. V. R. Rodriguez, M.V.R. (Orgs.). Smart cities, cidades inteligentes nas dimensões: planejamento governança, mobilidade, educação e saúde. [Livro Digital]. (Cap. 1, pp. 20-32). Rio de Janeiro: UFF/LITS/UNISUAN.

Herculano, S. (2002). Riscos e desigualdade social: a temática da Justiça Ambiental e sua construção no Brasil. Anais do I Encontro da ANPPAS, Indaiatuba (SP).

Herculano, S. (2008). O clamor por justiça ambiental e contra o racismo ambiental. Revista de Gestão Integrada em Saúde do Trabalho e Meio Ambiente, 3(1), 1-20, artigo 2.

Hornik, K., Cutts, B., \& Greenlee, A. (2016). Community theories of change: linking environmental justice to sustainability through stakeholder perceptions in Milwaukee, (WI, USA). International Journal of Environmental Research and Public Health, 13(10), 979-992.

Lafortezza, R., Chen, J., Van Den Bosch, C. K., \& Randrup, T. B. (2018). Nature-based solutions for resilient landscapes and cities. Environmental Research, 165, 431-441.

Loh, P. Community-university collaborations for environmental justice. (2016). New Solutions: A Journal of Environmental and Occupational Health Policy, 26(3), 412-428. 


\section{JUSTIÇA AMBIENTAL E PLANEJAMENTO URBANO: CONSTRUINDO RESILIÊNCIA EM COMUNIDADES VULNERÁVEIS}

Madeiros, H., Grigio, A., \& Pessoa, Z. (2018). Desigualdades e justiça ambiental: um desafio na construção de uma cidade resiliente. Revista de Geografia e Ordenamento do Território (GOT), 13, 247-265.

Meyer, M., Hendricks, M., Newman, G., Horney, J., Berke, P., Masterson, J., Sansome, G., Cousinsd, T., Van Zandtd, S., \& Cooper, J. (2018). Participatory Action Research: Tools for Disaster Resilience Education. International Journal of Disaster Resilience in the Built Environment, 9(4-5), 402-419.

Pires, L. R. G. M. (2020). Cidade inteligente e a aparente crise regulatória. In: A. L. A. Guedes, C. A. P. Soares, \& M. V. R. Rodriguez, M.V.R. (Orgs.). Smart cities, cidades inteligentes nas dimensões: planejamento governança, mobilidade, educação e saúde. [Livro Digital]. (Cap. 5, pp. 71-82). Rio de Janeiro: UFF/LITS/UNISUAN.

Rosenthal, J. K., \& Brandt-Rauf, P. W. (2006). Environmental planning and urban health. Annals of the Academy of Medicine of Singapore, 35(8), 517-22.

Santos, M. (1993). A urbanização Brasileira. São Paulo: Editora de Humanismo, Ciência e Terminologia HUCITEC.

Santos, M. (2004). Por uma geografia nova: da crítica da geografia a uma geografia crítica. 6.ed. São Paulo: Editora da Universidade de São Paulo.

Sarlet, I. W. (2003). O direito fundamental à moradia na Constituição: algumas anotações a respeito de seu contexto, conteúdo e possível eficácia. Direito e Democracia, 2(4), 327 383.

Sarlet, I. W. (2009). Dimensões da dignidade: ensaios de filosofia do direito e direito constitucional. 2.ed. Porto Alegre: Livraria do Advogado.

Sarlet, I. W. (2012). A eficácia dos direitos fundamentais. 11.ed. Porto Alegre: Livraria dos Advogados.

Shepard, P. M., \& Corbin-Mark, C. (2009). Climate justice. Environmental Justice, 2(4), 163-166. 